\title{
Use of prospective hospital surveillance data to define spatiotemporal heterogeneity of malaria risk in coastal Kenya
}

\author{
Donal Bisanzio ${ }^{1,8^{*}}$, Francis Mutuku², Angelle D. LaBeaud ${ }^{3}$, Peter L. Mungai ${ }^{4}$, Jackson Muinde ${ }^{5}$, Hajara Busaidy ${ }^{6}$, \\ Dunstan Mukoko ${ }^{7}$, Charles H. King ${ }^{4}$ and Uriel Kitron ${ }^{1}$
}

\begin{abstract}
Background: Malaria in coastal Kenya shows spatial heterogeneity and seasonality, which are important factors to account for when planning an effective control system. Routinely collected data at health facilities can be used as a cost-effective method to acquire information on malaria risk for large areas. Here, data collected at one specific hospital in coastal Kenya were used to assess the ability of such passive surveillance to capture spatiotemporal heterogeneity of malaria and effectiveness of an augmented control system.
\end{abstract}

Methods: Fever cases were tested for malaria at Msambweni sub-County Referral Hospital, Kwale County, Kenya, from October 2012 to March 2015. Remote sensing data were used to classify the development level of each monitored community and to identify the presence of rice fields nearby. An entomological study was performed to acquire data on the seasonality of malaria vectors in the study area. Rainfall data were obtained from a weather station located in proximity of the study area. Spatial analysis was applied to investigate spatial patterns of malarial and nonmalarial fever cases. A space-time Bayesian model was performed to evaluate risk factors and identify locations at high malaria risk. Vector seasonality was analysed using a generalized additive mixed model (GAMM).

Results: Among the 25,779 tested febrile cases, $28.7 \%$ were positive for Plasmodium infection. Malarial and nonmalarial fever cases showed a marked spatial heterogeneity. High risk of malaria was linked to patient age, community development level and presence of rice fields. The peak of malaria prevalence was recorded close to rainy seasons, which correspond to periods of high vector abundance. Results from the Bayesian model identified areas with significantly high malaria risk. The model also showed that the low prevalence of malaria recorded during late 2012 and early 2013 was associated with a large-scale bed net distribution initiative in the study area during mid-2012.

Conclusions: The results indicate that the use of passive surveillance was an effective method to detect spatiotemporal patterns of malaria risk in coastal Kenya. Furthermore, it was possible to estimate the impact of extensive bed net distribution on malaria prevalence among local fever cases over time. Passive surveillance based on georeferenced malaria testing is an important tool that control agencies can use to improve the effectiveness of interventions targeting malaria (and other causes of fever) in such high-risk locations.

Keywords: Malaria/epidemiology, Malaria/statistics and numerical data, Distribution/spatial, Public health surveillance, Spatiotemporal analysis, Geographic mapping, Geographic information systems, Kenya

\footnotetext{
*Correspondence: donal.bisanzio@zoo.ox.ac.uk

${ }^{8}$ Present Address: Department of Zoology, University of Oxford,

Oxford, UK

Full list of author information is available at the end of the article
} 


\section{Background}

The World Health Organization (WHO) estimates that almost $90 \%$ of malaria-associated mortality occurs in endemic countries of sub-Saharan Africa [1]. Malaria is endemic in Kenya but, as is also the case in the rest of sub-Saharan Africa, transmission intensity has been drastically reduced since early 2000s [2, 3]. This decline is associated with an intensive anti-malaria campaign [4-7] based on massive distribution of long-lasting insecticidetreated bed nets (LLINs), indoor residual spraying (IRS) and the introduction of artemisinin-based combination therapy (ACT) as the first-line treatment for malaria [8, 9].

Malaria transmission patterns are modulated by the interactions between environmental, meteorological and socio-economic factors [10-13]. Spatial heterogeneity of malaria manifests in hot spots of transmission at different ranges of geographical scale [10, 14, 15]. Temporally, these hot spots show a seasonal pattern as well as interannual variability $[11,15]$. Early detection and prediction of hot spots through an effective surveillance system can help target interventions aimed at reducing the impact of malaria in these areas.

Malaria hot spots have been identified by both passive and active surveillance systems in Kenya. Both systems can capture the space-time pattern of malaria and the impact of control systems on the disease's morbidity [3, 16 , 17]. However, in comparison to active surveillance, prevalence and incidence obtained by passive surveillance are more susceptible to population characteristics (e.g., education, wealth status) as well as distance from health care facilities $[18,19]$. However, passive surveillance can cover a much larger area at a lower cost compared to active surveillance [15, 20], making it an important monitoring and evaluation tool for policymakers who chose to further enhance their control programs after an initial, but limited, reduction in malaria within endemic areas $[3,9,21,22]$. In order to use data from health care facilities to estimate effectiveness of control programs, the passive surveillance system has to be based on an adequate testing system [23]. Following WHO guidelines [24], Kenya's public health system has implemented a diagnosis-based malaria treatment policy for all age groups [9]. This policy has streamlined the collection of countrywide data that can be used to target areas with high resource needs for intervention.

Improved malaria testing practices at health care facilities in Kenya have indicated that a high proportion of febrile cases are not linked to Plasmodium infection [25]. Many diseases present in sub-Saharan Africa can manifest malaria-like symptoms, and only testing can lead health care practitioners to make correct diagnoses and subsequently prescribe the correct treatment [26]. While some of these diseases are well known and endemic in Kenya (e.g., influenza, pneumonia, enteric fevers), others are considered to be emerging (e.g., Rift Valley fever, chikungunya, dengue) [27-29].

In this study, data collected from one hospital located in coastal Kenya were used to: (1) calculate the fraction of fevers due to malaria; (2) describe the space-time pattern of malaria occurrence; (3) identify areas where non-malarial fever illnesses were more frequent; and, (4) assess the ability of passive surveillance to capture the short- and long-term effects of enhanced LLIN distribution for local populations at risk for malaria.

\section{Methods}

\section{Ethical approval}

Ethical approval and oversight for this study was provided jointly by the Institutional Review Board of the University Hospital Case Medical Center of Cleveland (Protocol 11-07-45) and by the Ethical Review Committee of the Kenya Medical Research Institute (KEMRI) (Non-SSC Protocol 087). The present analysis used aggregated, anonymized data reported to the investigators by the study health facilities as part of ongoing public health surveillance for malaria.

\section{Setting and data collection of incident febrile illnesses}

The study was conducted in Msambweni sub-County Referral Hospital, Kwale County, Kenya $\left(4.48^{\circ} \mathrm{S}, 39.48^{\circ} \mathrm{E}\right)$. The area is rural, and malaria is endemic, as are various other parasitic diseases $[5-7,10,30]$. The climate is characterized by monsoonal 'long rains' (April-June, LRS) and 'short rains' (October-December, SRS) rainy seasons, and by hot (January-March, HDS) and cool (JulySeptember, CDS) dry seasons. Although rains are more frequent during the rainy seasons, rains also fall during the dry seasons. An extended bed net distribution program for all area households was implemented in the study area during August 2012 as part of the national malaria control program.

From October 2012 to March 2015, clinic-based surveillance of febrile cases was conducted at Msambweni Hospital. The hospital has 155 in-patient beds and serves as one of the main of health care providers in Kwale County. All patients presenting with fever (axillary temperature of $37.5{ }^{\circ} \mathrm{C}$ or above) or having history of fever were tested for malaria (Plasmodium spp. infection) using a standard, quality-controlled, Giemsa-stained, blood smear technique performed by trained parasitology technicians. For this study, only febrile illness cases positive by microscopy were counted as malaria diagnoses. Limited, fully anonymized data were provided by the hospital about patient age, gender and community of origin. Because patient identity was masked, the analyses 
could not be adjusted for repeated episodes of fever in the same person.

\section{Community characterization}

Population and environmental characteristics were obtained for each community. Population size was based on the 2009 national Census [31]. Each community was characterized as 'less-developed' or 'more-developed', based on proportion of houses with thatched roof, spatial arrangement of households, and typology of road (road class and surface material), using high resolution satellite images from Google and Bing mapping systems acquired during 2006 and 2007, applying Quantum GIS (QGIS) [32] dedicated plug-ins. Information on the road network of the study area was gathered using data downloaded from the Global Roads Open Access Data Set website [33]. Google and Bing mapping systems were used to identify presence of rice fields adjacent to or within $(\leq 1 \mathrm{~km})$ of each community.

\section{Rainfall data}

Historical weather data were obtained from October 2012 to March 2015 from the archive of Weather Underground website [34], recorded at the weather station located at the Moi International Airport of Mombasa (HKMO, 4.04 ${ }^{\circ} \mathrm{S}$, $39.59^{\circ} \mathrm{E}$ ). The Moi International Airport of Mombasa is the closest weather station to the study area, located $56.6 \mathrm{~km}$ to the north of Msambweni Hospital.

\section{Entomological survey}

Seasonal patterns of mosquito abundance were estimated using data obtained during a four-year (April 2009April 2013), multi-village, entomological study in Kwale County $[10,35]$. The entomological surveillance targeted four villages that were representative of communities of the south coast of Kenya, and the group of surveyed villages included two communities, Milalani and Nganja, that were part of the current study.

\section{Spatial analysis}

Getis' $G i^{*}(d)$ local statistic [34] was applied to identify spatial clusters of high and low proportion of febrile cases associated with Plasmodium infection. Given the distribution of communities in the study area (Fig. 1), an automatic procedure (e.g., K nearest neighbors, distance threshold) could not be used to determine the distance weight for the $G i *(d)$ test. Instead, a neighboring network was created ad hoc, in which the links were based on Euclidian distance and road connections between villages (Additional file 1). Significance $(\mathrm{p}<0.05)$ was evaluated by comparing expected values under the null hypothesis of complete spatial randomness (based on 999 Monte Carlo permutation) with observed data.
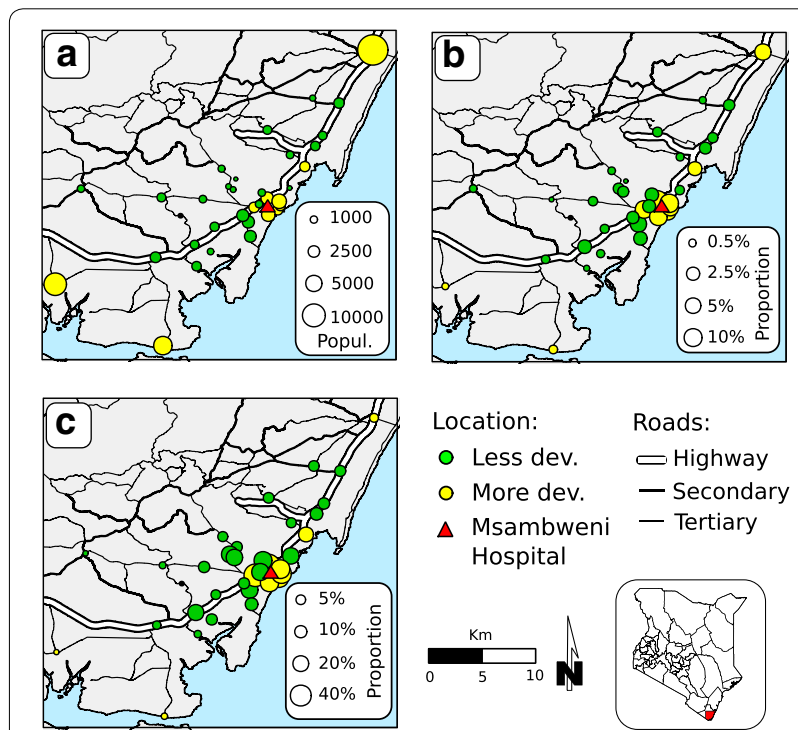

Fig. 1 Characteristics and proportion of recorded febrile cases by community. a Village population (circles, where circle size indicates relative population size and color indicates level of development); b proportion of community population enrolled in the study as febrile cases at Msambweni Hospital (hospital indicated by red triangle, village circle size indicates relative proportion value); c proportion of admitted febrile cases from each community. Villages are categorized as less developed (green) or more developed (yellow). Road networks (major and minor roads) are also shown

\section{Statistical modelling}

Structured additive regression (STAR) models [33] were used to quantify the contribution of demographic attributes of patients, environmental characteristics of villages and seasonality to the probability of a febrile case being positive for Plasmodium infection. A STAR model was performed in order to account for spatial autocorrelation and seasonality of proportion of Plasmodium infection among febrile cases. The full model formula was:

$$
\begin{aligned}
& \text { Malaria case }(1,0)=f_{1}(\text { Age })+f_{2}(\text { Month }) \\
& \left.\quad+f_{3} \text { (LLINs distr. }\right)+\beta_{1} * \text { Gender } \\
& +\beta_{2} * \text { Dist Shore }+\beta_{4} * \text { Rice }+\beta_{5} *(\text { Month } * \text { Rice }) \\
& +B_{6} *(\text { Development })+f_{\text {spat }}(\text { Communities }) \\
& + \text { rand }(\text { Communities }) .
\end{aligned}
$$

The model included four linear predictors: patient gender (Gender), distance from shoreline in $\mathrm{km}$ (Dist Shore), presence of rice fields nearby or within $(\leq 1 \mathrm{~km})$ the community (Rice), and community development level (Development). The model had a factor to represent the interaction between month and presence of rice fields (Month $^{*}$ Rice). Patient age and enrolment month were included as non-linear predictors $\left(f_{1}(\right.$ Age $), f_{2}$ (Month) $)$ modeled as natural cubic B-splines with a second-order random walk penalty. The effect of the mass distribution 
of LLINs performed in August 2012 was represented using a non-linear function (cubic B-spline) of the logarithm of number of months since the time between bed net deployment and each patient's subsequent febrile episode $\left(f_{3}\right.$ (LLINs distr. $\left.)\right)$.

The model contains a spatial correlated random effect, $f_{\text {spat }}$ (Communities) modeled as a Markov random field. To describe the spatial relationship between villages, the neighboring network created ad hoc to perform the Getis' $G i^{*}(d)$ was used (Additional file 1). The distance between each connected community was used as the weight of each network link. The model also had an unstructured random effect, rand(Communities), to consider heterogeneity among communities, that was not accounted by the model covariates, and adjusted the model for the distance $(\mathrm{km})$ of community centre from the hospital.

Multivariate logistic regressions were used to estimate the associations of rice fields, seasonality and collection year with presence of female anopheline mosquitoes during each house collection session using a generalized additive mixed model (GAMM) [36] that took into account differences in sampling schedules between years (Additional file 2). Given the differences in sensitivity of sampling method applied during collection [35], each model was adjusted for the sampling techniques applied during each mosquito collection. The full model formula was:

$$
\begin{aligned}
& \text { Presence of Anopheles sp./Anopheles funestus / } \\
& \text { Anopheles gambiae }(1,0)=f_{1}(\text { Month })+\beta_{1} * \text { Rice } \\
& \quad+\beta_{2} * \text { Year }+ \text { rand }(\text { Village }) .
\end{aligned}
$$

Collection month was included in the model as a nonlinear predictor $\left(f_{1}(\right.$ Month $\left.)\right)$. Presence of rice fields near or within the community (Rice) and collection year (Year) were included as linear predictors. The variable rand (Village) represents the random effect of the four villages where the collection was performed.

Multi-model selection approach based on Akaike Information Criteria (AIC) was performed to find the best models for the febrile illness data and the entomological data [37]. The $\triangle \mathrm{AIC}$ was calculated among all proposed models as the difference between their AIC and the one with the lowest AIC value. All those models showing a $\triangle \mathrm{AIC}<2$ were included in the set of best models [37]. Presence of spatial and temporal autocorrelation in model residuals was tested using Moran's I and DurbinWatson test, respectively. Residuals of the entomological model were only tested for temporal autocorrelation due to the low number of sampled villages.

\section{Other statistical analysis}

Association between distance from the Msambweni Hospital and the number of in-patients admitted from each community was tested using Spearman's correlation. Fisher's exact test was applied to evaluate differences of proportion of malaria febrile cases between females and males, and between less-developed and more-developed communities. The Fisher's exact test was also applied to compare the proportion of houses positive to the presence of vectors between seasons. Proportions of febrile cases diagnosed with malaria were compared between age groups and seasons using Fisher's least significant difference (HSD) test [38]. Wilcoxon rank-sum test was used to compare number of enrolled cases between seasons.

\section{Geographic information system and statistical tools}

Data were stored in a geographic information system (GIS) created with QGIS software [39]. All geographic data were georeferenced using Universal Transverse Mercator (UTM) Zone 37 South, datum WGS84. Getis'Gi* $(d)$ test was performed using Easyspat (Bisanzio et al. in prep.). Modelling was performed using the statistical software Bayes $\mathrm{X}$ through the $\mathrm{R}$ software interface R2BayesX [33]. All other analyses and data cleaning were performed using basic functions embedded in R software [40].

\section{Results}

\section{Village characteristics}

Of the 34 villages included in the study, 24 (70.6\%) were classified as less developed (Fig. 1). Presence of rice fields was recorded in 21 communities $(61.7 \%)$, and most of these (18/21, $85.7 \%$ ) were classified as less developed.

The average distance from the shoreline and the average village elevation were $3.3 \mathrm{~km}(\mathrm{SD}=2.9)$ and $29.8 \mathrm{~m}$ $(\mathrm{SD}=23.5)$ above sea level (masl), respectively. The median population size was 1698 [interquartile range $(I Q R)=1052-2726]$ (Fig. 1a). The average distance of villages from Msambweni Hospital was $8.4 \mathrm{~km}(\mathrm{SD}=6.6)$ (Fig. 1); for each community, the proportion of all patients treated at Msambweni Hospital was negatively correlated to its distance from the hospital (Spearman's $\rho=-0.86, \mathrm{p}<0.01$, Fig. 1c).

\section{Febrile cases}

Demographic characteristics and malaria prevalence of tested individuals are shown in Table 1 . Over the study period, 25,779 febrile cases who sought health care at Msambweni County Referral Hospital were enrolled in the study. The median age of patients was 5 years (IQR $=2-21)$, with more females than males (Table 1 ). Overall, the blood smears of $7424 / 25,779$ patients (28.7\%) were positive for Plasmodium species. Of all patients, 16,980 (65.8\%) were under 16 years of age, and the prevalence of malaria in this age group (34.7\%) 
Table 1 Demographic characteristics of tested individuals having febrile illness, and their sub-group malaria prevalence by gender, age group and community type

\begin{tabular}{lll}
\hline & $\begin{array}{l}\text { Sub-group } \\
\text { proportion among } \\
\text { the 25,779 patients } \\
\text { tested (\%) }\end{array}$ & $\begin{array}{l}\text { Fraction of } \\
\text { tested sub-group } \\
\text { subjects found } \\
\text { to have malaria (\%) }\end{array}$ \\
\hline Sex & & \\
Female & 58.4 & 26.2 \\
Male & 41.6 & 32.4 \\
Age group & & \\
0-5 & 46.9 & 28.7 \\
6-10 & 12.5 & 49.8 \\
11-15 & 6.1 & 44.3 \\
16-20 & 6.2 & 24.3 \\
21-25 & 7.4 & 18.8 \\
26-30 & 6.3 & 16.1 \\
$>30$ & 14.6 & 10.7 \\
Type of community & & \\
More developed & 33.5 & 34.7 \\
Less developed & 66.5 & 25.7 \\
\hline
\end{tabular}

was significantly higher than in adults (17.3\%, Fisher's exact test, $\mathrm{p}<0.01$ ) (Fig. 2). Prevalence in male patients $(32.4 \%)$ was higher than in female patients $(26.2 \%$, Fisher's exact test, $\mathrm{p}<0.01)$. Febrile cases from the less developed communities showed significantly higher prevalence of malaria $(34.7 \%)$ than those from the more developed villages ( $25.7 \%$, Fisher's test, $\mathrm{p}<0.01)$ (Fig. 2). However, among all less developed communities, those villages with rice fields within their borders or nearby had significantly higher malaria proportion (35.8\%) among enrolled febrile cases than less developed communities without rice fields $(29.7 \%$, Fisher's exact test, $\mathrm{p}<0.01$ ).

The number and proportion of enrolled febrile cases was associated with seasonality and showed two annual peaks during the LRS and during the SRS in 2013, and at the beginning of HDS and during SRS in 2014 (Fig. 2). This seasonal pattern was consistent for all febrile cases, both non-malarial and malaria-associated (Fig. 2). A significantly lower number of febrile cases was recorded during the HDS (Wilcoxon rank-sum test, $\mathrm{p}<0.05$ ). The seasonal trends of enrolled cases were similar in less developed and more developed communities (Fig. 2). The respective proportions of febrile cases with malaria were not significantly different between less and more developed communities during the HDS and the LRS (Fisher's exact test, $p>0.05$, Fig. 3). However, during the CDS and the SRS, a significantly higher (Fisher's test, $\mathrm{p}<0.05$ ) proportion of febrile cases positive to malaria were from less developed communities (Fig. 3).

\section{Spatial analysis}

The proportion of febrile cases who tested positive for malaria was spatially autocorrelated during the study period $(G i *(d)$ test, Fig. 4). Clusters of communities with high (hot spots) and low (cold spots) proportion of malaria-associated febrile illness were detected in every season except for the HDS. Most of the hot spots were around less developed communities and situated farther from the coast $\left(G i^{*}(d)\right.$ test, $\mathrm{p}<0.05$, Fig. 4). Low levels of malaria infections (cold spots) were clustered $\left(G_{i}^{*}(d)\right.$, $\mathrm{p}<0.05$, Fig. 4) around developed communities. No clusters were detected during HDS, when fewer Plasmodium infections were detected among patients coming from most of these communities (Fig. 4).

\section{Model results}

The best model included variables of the full model formula (Additional file 3). Detailed results from the logistic STAR model are presented in Table 2 and Figs. 5 and 6. Males (Table 2), and children in the three to 18 years age range (Fig. 5) were significantly more likely to test positive for malaria. During the last 2 months of the HDS and first part of the LRS, patients were less likely to test positive for Plasmodium infection than in the CDS and SRS. Seasonal effects showed an interaction with presence of rice fields (Table 2).

The mass distribution of LLINs in August 2012 was significantly associated with a reduced probability that febrile illness would test positive for malaria (Fig. 5c). However, the positive effect of the distribution of LLINs rapidly decreased and apparently disappeared by the 14th month post intervention (Fig. 5c).

Febrile patients from communities further from shoreline were more likely to test positive for Plasmodium infection (Table 2). The probability of a febrile case from less developed communities to have malaria was $50 \%$ higher, but this result was not significant (Table 2). The spatial structure effect included in the model identified a hot spot of higher risk for malaria in the central part of the study area (Fig. 6), with patients from that area three times more likely to test positive for malaria. By contrast, patients from communities in the southern part of study area were significantly less likely to test positive for malaria (Fig. 6). No spatial (Moran's I, $\mathrm{p}=0.23$ ) and temporal autocorrelation (Durbin-Watson test, $\mathrm{p}=0.64$ ) were found in model residuals. These findings showed that the model was able to capture the spatial-temporal component of the data.

\section{Mosquito infestation}

During the study period, 2009-2013, 2463 households were surveyed for a total of 4125 house collections. Presence of female Anopheles mosquitoes was recorded in 


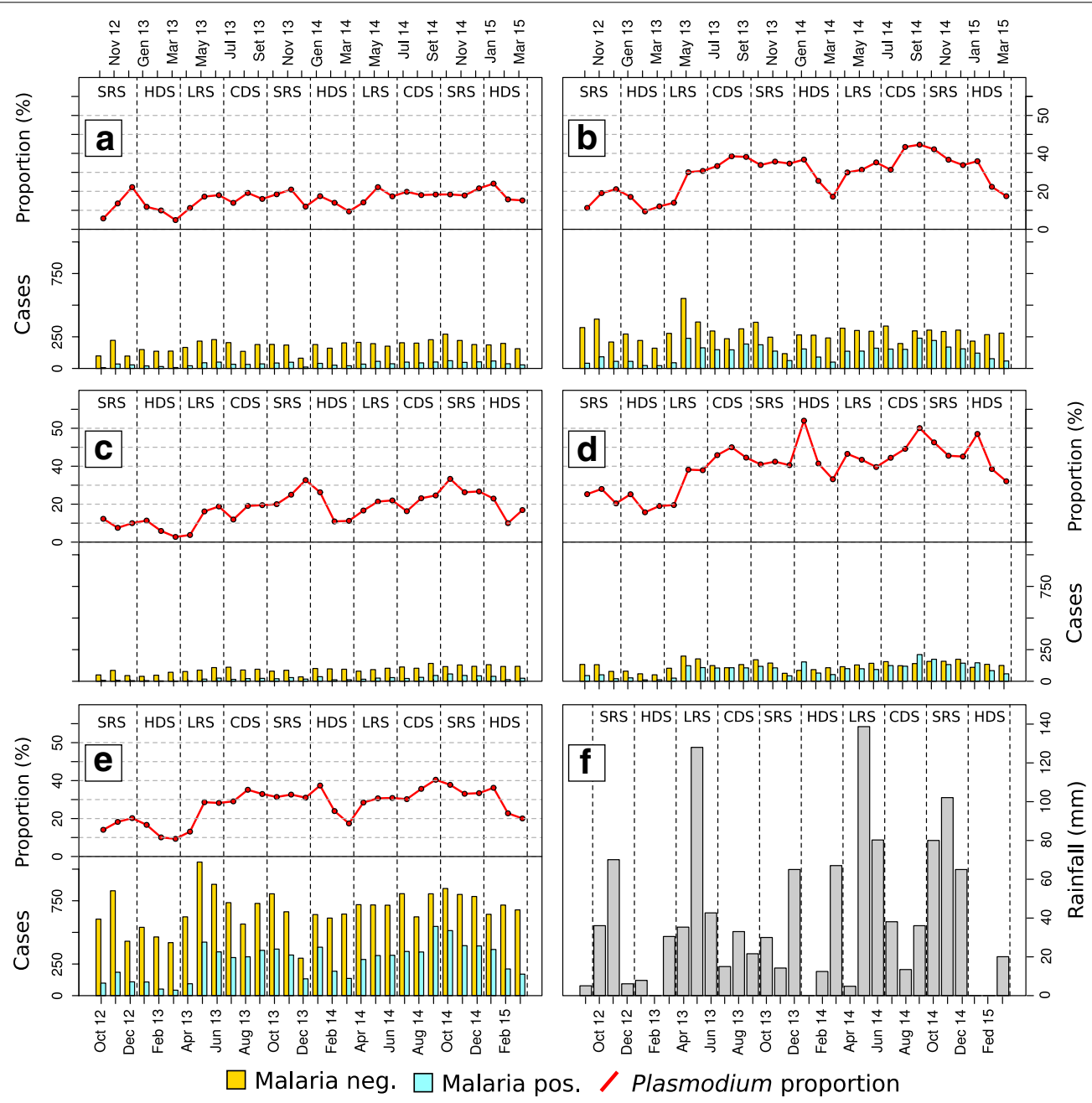

Fig. 2 Monthly number of malaria-positive and -negative febrile cases, proportion of Plasmodium infections among febrile cases, and monthly cumulative rainfall. Figure panels show proportion of Plasmodium among febrile cases in children and in adults from less developed and more developed communities: adults (a) and children under 15 years (b) living in more developed areas; adults (c) and children (under 15 years); (d) living in less developed areas; data for all subjects enrolled in the study are shown in e. f Shows monthly rainfall recorded during the study period

461 households (18.7 \%). The proportion of houses positive for presence of An. funestus and for An. gambiae were $11.4 \%(282 / 2463)$ and $10.4 \%(255 / 2463)$, respectively. Co-infestation by both species was recorded in 76 houses $(3.1 \%)$. The proportion of positive houses was higher during the rainy seasons (Fisher's exact test, $\mathrm{p}>0.05$, Table 3).

\section{Model results for entomological collection}

Model selection results showed that all variable of the full formula were included in the best model (Additional file 4). Presence of female Anopheles mosquitoes showed significant seasonality, with the risk of mosquito infestation higher during rainy seasons (Fig. 6). The probability for detection of both An. gambiae and of An. funestus infestations was significantly higher in the LRS and lower in the CDS (Fig. 7). The probability for houses to be infested with Anopheles mosquitoes was significantly lower in 2009, the first year of collection (Table 4). Model results also indicated an association of presence of rice fields near a village with higher probability of infested houses, but this effect was not significant (Table 4). Model residuals did not show temporal autocorrelation (Durbin-Watson test, $\mathrm{p}=0.37$ ).

\section{Discussion}

Fever is the most common symptom exhibited by people seeking health care in Kenya [41-43]. The study results demonstrated that georeferenced information obtained through testing febrile cases for malaria can be 


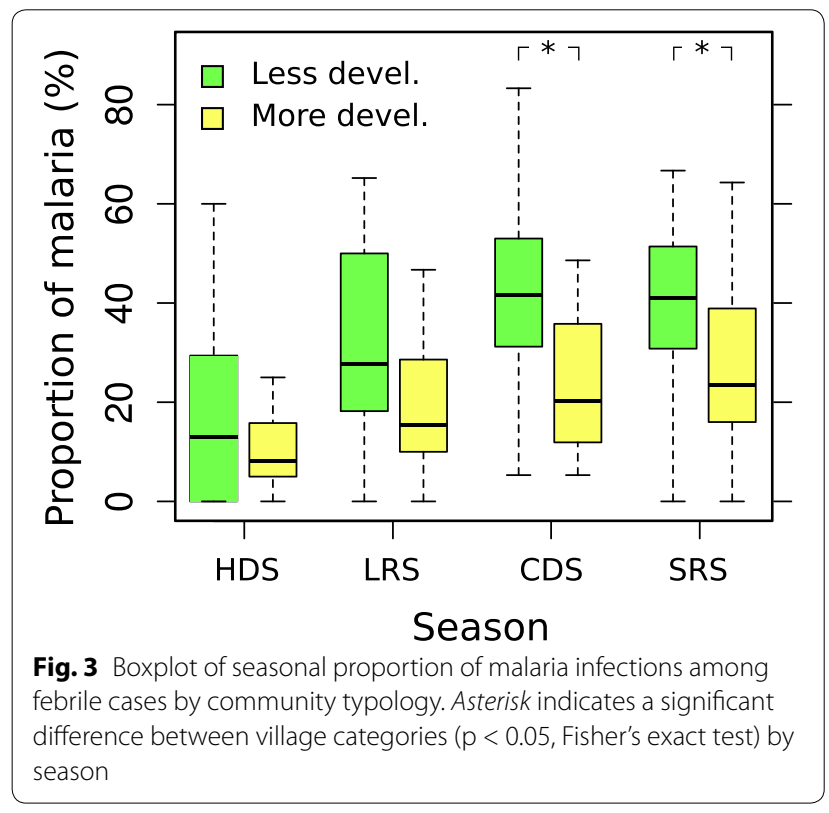

used to evaluate the spatial and temporal heterogeneity in patterns of Plasmodium infection in a district-level or sub-county sized study area. Additionally, these data allowed associating a significant effect on the prevalence of malaria among febrile cases with mass deployment of LLINs, (which occurred during the summer of 2012). Finally, the study findings highlighted the presence of clusters of low prevalence of malaria in febrile cases in communities closer to the Indian Ocean shoreline.

The prevalence of malaria among febrile cases increased following the start of the two rainy seasons, when the frequent rains likely increased the abundance of breeding sites for Anopheles mosquitoes. This effect was more marked in the less developed communities, and could also be statistically linked to the presence of nearby rice paddies. In coastal Kenya, past research has indicated that rice fields become flooded during the rainy seasons and become optimal breeding sites for Anopheles mosquitoes for several months thereafter $[44,45]$. The flooding period of paddies typically results in an increase of vector abundance in adjacent communities, likely followed by higher levels of transmission levels of Plasmodium spp. [46].

The seasonal trend of malaria prevalence among febrile cases was significantly associated with mosquito infestation levels recorded in sampled households. A significant reduction was observed in the proportion of infested houses from 2009 to 2013. This can probably be linked to the mass LLIN distribution campaign performed in the study area [47], as similar control efforts have demonstrated a decrease in infestation levels elsewhere [48, 49]. The proportion of fever cases who tested positive for

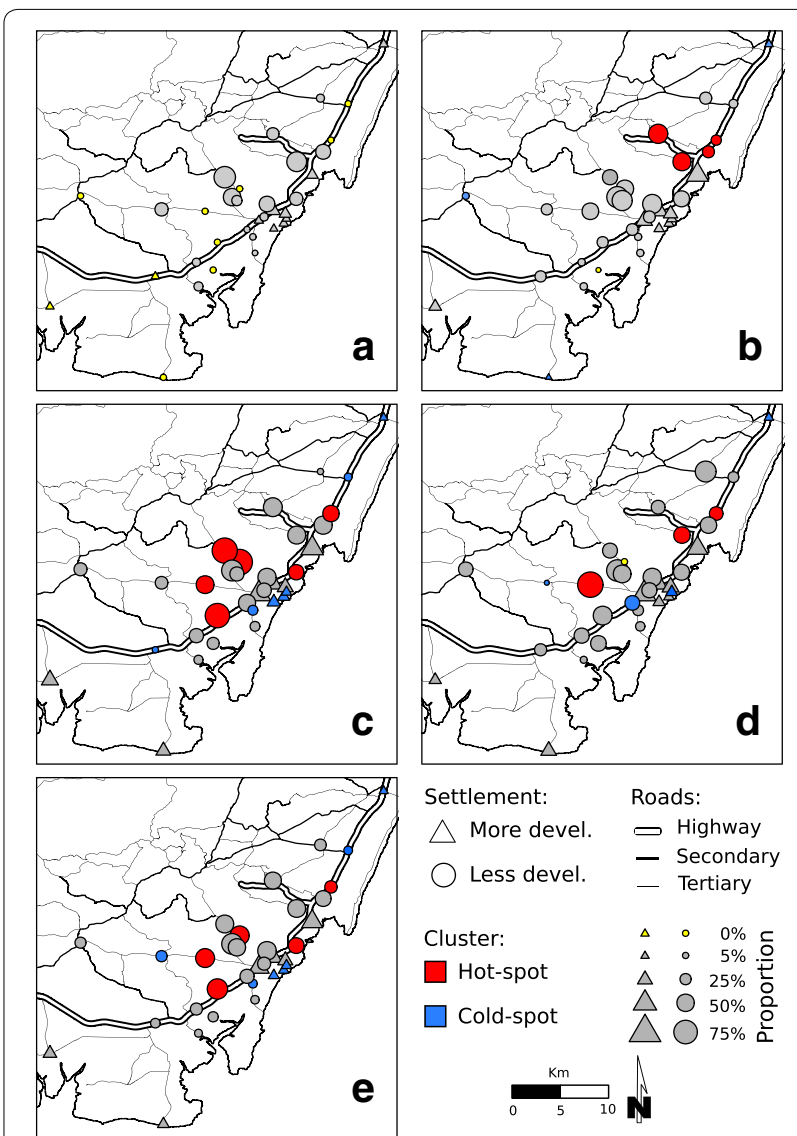

Fig. 4 Getis $G_{j}^{*}(d)$ cluster analysis of study communities based on their higher or lower proportion of malaria-associated febrile cases. The $G_{i}^{*}(d)$ test was used to identify significant community hotspot clustering (red circles) and/or cold-spot clustering (blue circles, $p<0.05$, based on 9999 permutations) during: a the hot dry season (HDS, Jan-Mar); b the long rainy season (LRS, Apr-Jun); c the cool dry season (CDS, Jul-Sept); $\mathbf{d}$ the short rainy season (SRS, Oct-Dec); and, e, over all periods

malaria decreased significantly in the months following the mass deployment of LLINs. However, the observed reduction lasted less than 18 months after the distribution of LLINs. These findings are consistent with the previously recorded mean time of effectiveness of LLINs in coastal Kenya [50]. Moreover, studies have shown that bed net use declines after approximately 1 year of utilization as the bed nets are perceived as less effective due to accumulated damage [51-53].

Spatial analysis identified geographical hot spots of malaria risk in the central portion of the study area. The same areas were also indicated as being at high risk by the STAR model, which simultaneously accounted for the presence of rice fields, seasonality and each community's level of development. Model results suggested the presence of additional factors not included as predictors 
Table 2 Predictors, based on logistic regression modelling, of the relative odds that a febrile case was associated with Plasmodium infection

\begin{tabular}{|c|c|}
\hline \multirow[t]{2}{*}{ Predictor } & \multirow{2}{*}{$\begin{array}{l}\text { Value } \\
\text { Odds ratio }(95 \% \mathrm{Cl})\end{array}$} \\
\hline & \\
\hline \multicolumn{2}{|l|}{ Linear fixed effect } \\
\hline Sex: male & $1.28(1.12 ; 1.37)^{*}$ \\
\hline Distance to the shoreline $(\mathrm{km})$ & $1.10(1.01 ; 1.24)^{*}$ \\
\hline Rice field presence & $1.48(0.71 ; 1.74)$ \\
\hline No. months with rice field presence ${ }^{a}$ & $1.16(1.08 ; 1.29)^{*}$ \\
\hline Less developed & $1.15(0.66 ; 1.99)$ \\
\hline \multicolumn{2}{|l|}{ Smooth effect ${ }^{b}$} \\
\hline Age & * \\
\hline Month & * \\
\hline Time since LLIN distribution & * \\
\hline \multicolumn{2}{|l|}{ Random effect } \\
\hline Village & Variance $=0.6$ \\
\hline Structured spatial effect ${ }^{c}$ & * \\
\hline \multicolumn{2}{|l|}{${ }^{*} \mathrm{p}<0.05 ;{ }^{* *} \mathrm{p}<0.01$} \\
\hline \multicolumn{2}{|l|}{ a As counted from 1 to 12 months } \\
\hline \multicolumn{2}{|c|}{$\begin{array}{l}\text { b Only the significance of factors for age, month and time passed since mass } \\
\text { distribution of LLINs is indicated; the smooth functions of these predictors are } \\
\text { shown in Fig. } 5\end{array}$} \\
\hline \multicolumn{2}{|c|}{$\begin{array}{l}\text { ' Only the significance of structured spatial effect is indicated; the predictors are } \\
\text { shown in Fig. } 6\end{array}$} \\
\hline
\end{tabular}

in the performed model that may also play an important role in the spatial heterogeneity of malaria prevalence in surveyed populations. For instance, the model did not include information regarding the socio-economic status of enrolled individuals or other information concerning potentially important larval sites, such as the presence of permanent or seasonal ponds. These factors could have further affected the spatial heterogeneity of malaria prevalence. Such breeding sites (flooded, wet areas) increase the risk of infection in the surrounding communities and, accordingly, malaria hot spots are often identified near these areas [10,54]. High malaria levels in poor communities can be attributed to the natural materials used to build houses (mud walls and grass-thatched roof), which provide optimal resting places for mosquitoes [55, 56]. However, the aforementioned environmental risk factors can also be found in some more developed communities, and these can increase the risk of malaria for people living in these areas as well [57]. This could explain why the STAR model identified some more developed communities as being at high risk of infection as well.

With regard to age, individuals aged three to 18 years showed a high probability of testing positive for malaria, and individuals 9 years of age had the highest estimated probability of malaria-positive fever. These results are consistent with previous findings based on active surveys
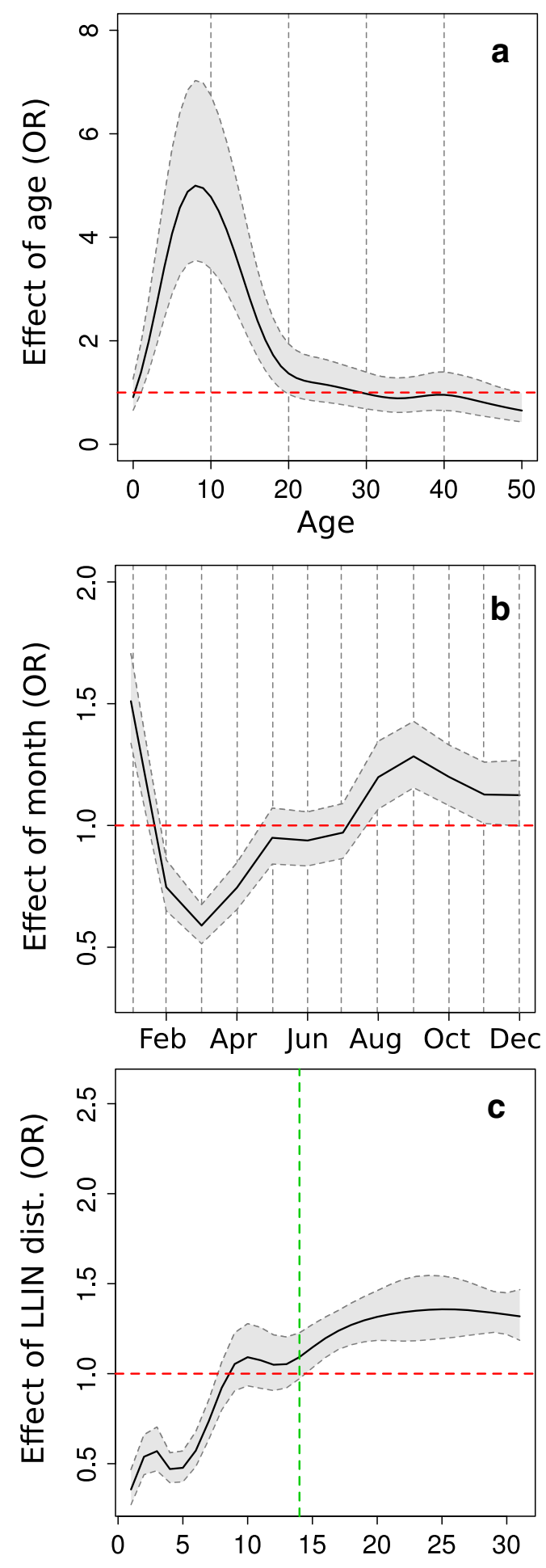

Months after LLIN dist.

Fig. 5 Age, month and time since last mass distribution of LLINs as non-linear predictors for the association of a febrile case with malaria infection obtained by the STAR model. a OR function of the age variable with $95 \% \mathrm{Cl}$; b OR function of the month variable with $95 \%$ $\mathrm{Cl} ; \mathbf{c}$ OR function of the time passed since mass distribution of LLINs with $95 \% \mathrm{Cl}$ 

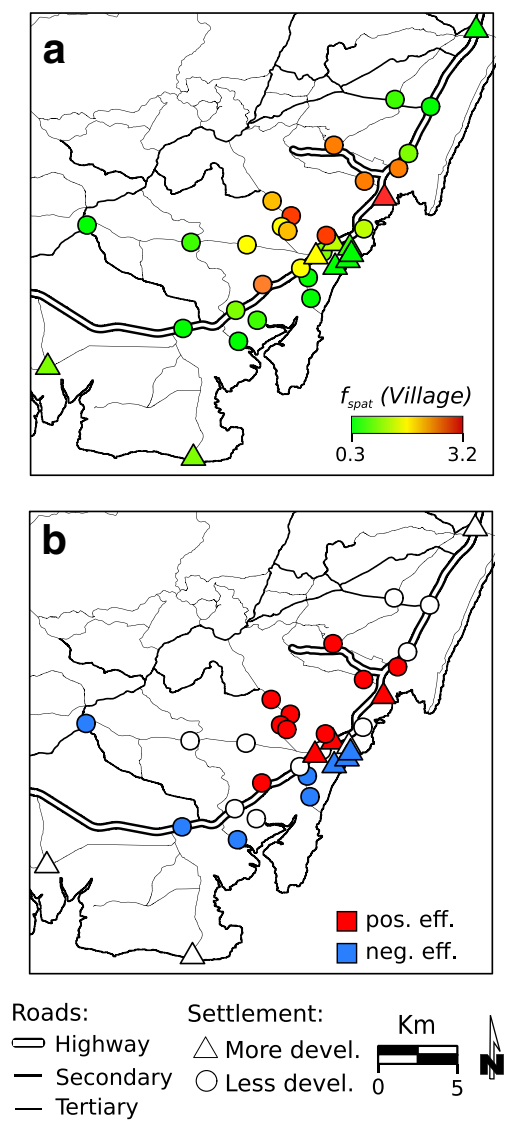

Fig. 6 Estimated effect of spatial structured covariate $f_{\text {spat }}$ (Village) on the association of fever with malaria infection obtained by STAR model. a Mean OR for malaria-related fever in each community; b Communities showing a significant $(p<0.05)$ negative or positive effect in their proportion of Plasmodium infections among their febrile cases

performed in communities of the study area [10]. Additional studies in Uganda and Western Kenya [15, 20] have also shown the effectiveness of passive surveillance in identifying age groups that should be targeted by control systems.
Collection of data at health care facilities is more costeffective than testing for malaria at the community level and can be easily maintained year round [15]. However, these types of data only include those community members who have sought medical attention. Information on malaria prevalence obtained by screening febrile cases cannot be used for accurate estimations of the true malaria prevalence in communities $[58,59]$. Nevertheless, the analyses demonstrated that data recorded at health facilities can be used to determine those areas where Plasmodium circulation is very high. Studies performed in Rwanda have shown that active surveillance informed by data previously collected by passive surveillance can be used to analyse malaria hot spots and identify the likelihood of asymptomatic cases at community level [54].

Among the tested febrile cases, $28.5 \%$ tested positive for malaria, which indicates that a wide proportion of febrile cases were due to other causes. Similar low malaria prevalence among febrile cases has been reported in other endemic countries of sub-Saharan Africa [25, 26, $60,61]$. In the study area, fever symptoms recorded in adults and inhabitants of more developed communities were more likely to be linked to non-malaria infections. Community clusters with high non-malaria febrile illness were found close to the coastline where levels of malaria prevalence are low [10]. Several prospective studies have found that febrile cases are often due to bacterial or viral diseases that mimic symptoms of malaria (e.g., dengue, chikungunya, leptospirosis, ehrlichiosis, brucellosis, enteric fevers) $[25,26]$. New, emerging diseases are often misdiagnosed as malaria because they have similar symptoms, and this may be especially common for individuals with dengue fever who are, in practice, often treated with anti-malarials but without benefit $[28,62]$.

\section{Conclusions}

The results obtained from data recorded at the Msambweni Hospital allowed describing temporal and spatial of malaria risk. These findings also suggested that

Table 3 Seasonal mosquito collections and proportion of houses positive for female anopheline mosquitoes, 2009-2013

\begin{tabular}{lccc}
\hline Study period (houses sampled) & An. funestus & An. gambiae & Anopheles genus \\
\hline All periods $(2463)^{\mathrm{a}}$ & $282(11.4 \%)$ & $255(10.4 \%)$ & $461(18.7 \%)$ \\
Season & & & $76(3.1 \%)$ \\
HDS $(787)^{\mathrm{b}}$ & $27(3.4 \%)$ & $59(7.5 \%)$ & $13(9.7 \%)$ \\
LRS $(1132)^{\mathrm{b}}$ & $114(10.1 \%)$ & $109(9.6 \%)$ & $198(17.4 \%)$ \\
CDS $(1126)^{\mathrm{b}}$ & $92(8.1 \%)$ & $39(3.4 \%)$ & $118(10.4 \%)$ \\
SRS $(1080)^{\mathrm{b}}$ & $76(7 \%)$ & $69(6.3 \%)$ & $128(11.8 \%)$
\end{tabular}

a Number of unique houses sampled

b Number of house collections 
Table 4 Predictors for presence of female anopheline mosquitoes based on multivariable logistic regression modelling

\begin{tabular}{|c|c|c|c|}
\hline Predictors & An. funestus & An. gambiae & Anopheles genus \\
\hline Fixed effect & OR (95 \% CI) & OR (95 \% CI) & OR (95 \% Cl) \\
\hline Presence of rice fields & $1.1(0.1-8.1)$ & $3.1(0.8-52.1)$ & $2.4(0.3-15.1)$ \\
\hline Years & $0.7(0.6-0.8)^{* *}$ & $0.7(0.6-0.8)^{* *}$ & $0.7(0.6-0.8)^{* *}$ \\
\hline Month ${ }^{\mathrm{a}}$ & $*$ & $*$ & $*$ \\
\hline Random effect & Variance & Variance & Variance \\
\hline Village & 1.1 & 3.3 & 1.5 \\
\hline
\end{tabular}

The models were adjusted for the collection technique applied in each mosquito collection

* $\mathrm{p}<0.05$; ${ }^{* *} \mathrm{p}<0.01$

a Only the significance of month covariate is indicated; the smooth function of this predictor is shown in Fig. 7
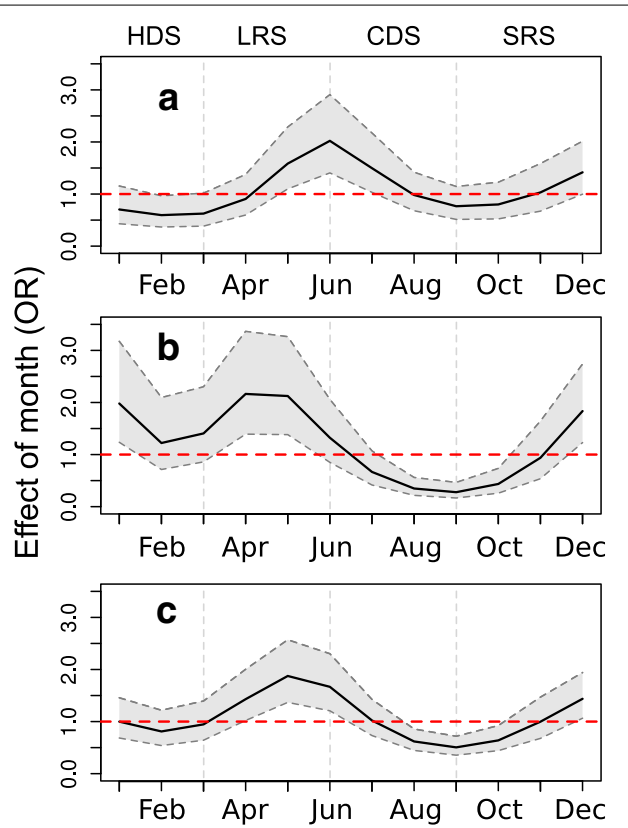

Fig. 7 Month as non-linear predictor for presence of female Anopheles mosquitoes obtained by GAMM. a OR function of An. funestus presence; $\mathbf{b}$ OR function of An. gambiae presence; c OR function of either Anopheles species presence

passive surveillance can be an effective and low-cost method to monitor the impact of mass LLIN distribution. This information can be used by surveillance and control agencies for more effective targeting of interventions based on LLIN distribution or IRS. Notably, the study results highlighted that the majority of fevers in coastal Kenya were not linked to smear-positive malaria. Improved testing for proper diagnosis of febrile cases at health care facilities could further define geographical hot spots and seasonality of these other competing causes of life-threatening and disabling infections, and, consequently, allow health systems to apply better, causespecific control.

\section{Additional files}

Additional file 1: The spatial structure used in the STAR model was the one used to perform the Gatis' $G i^{*}(d)$,

Additional file 2: Timing of mosquito sampling sessions per each village during study period 2009-2013 (Figure).

Additional file 3: Results of model selection performed to find the best model used to analyse febrile illness data (Table).

Additional file 4: Results of model selection performed to find the best model used to analyse entomological data (Table).

\section{Abbreviations}

LLINs: long-lasting insecticide-treated bed nets; ACT: artemisimin-based combination therapy; LRS: 'long rains' season; SRS: 'short rains' season; HDS: hot dry season; CDS: cool dry season; STAR: structured additive regression; GAMM: generalized additive mixed model; WHO: World Health Organization; IRS: indoor residual spraying; AIC: Akaike information criteria.

\section{Authors' contributions}

CHK, UK and FM conceived and designed the experiments; FM, ADL, PLM, JM, $H B$, and DM performed the experiments; DB, FM, UK, and CHK analysed the data; DB, UK, CHK, and FM wrote the paper. All authors read and approved the final manuscript.

\section{Author details}

${ }^{1}$ Department of Environmental Sciences, Emory University, Atlanta, GA, USA. ${ }^{2}$ Department of Environment and Health Sciences, Technical University of Mombasa, Mombasa, Kenya. ${ }^{3}$ Department of Pediatrics, Stanford University, Stanford, CA, USA. ${ }^{4}$ Center for Global Health and Diseases, Case Western Reserve University, Cleveland, OH, USA. ${ }^{5}$ Vector-Borne Diseases Control Unit, Msambweni County Referral Hospital, Kwale, Msambweni, Kenya. ${ }^{6}$ Ministry of Health Kwale County, Kwale, Mombasa, Kenya. ${ }^{7}$ Vector-Borne Diseases Control Unit, Ministry of Health, Nairobi, Kenya. ${ }^{8}$ Present Address: Department of Zoology, University of Oxford, Oxford, UK.

\section{Acknowledgements}

The authors thank communities of all the study villages for their continued support. We also thank the many Vector Borne Disease Control Unit (VBDCU) laboratory technicians, Gibson Waweru, Emily Kurera, Juma Hamadi, Collins Odawo, Henry Maleka, Joyce Bongo, Joyce Bandika, Huessin Mohamend Kitsongo, Lucy Njoka, Said Lipi, Peter Siema, Omar Kallum, Charles Ng'ang'a, Elton Mzungu, and Alex Osore for their dedication and meticulous microscopy. We shall not forget Christine Mambori Lucas for excellent data entry. This research was supported by NIH grants TW008067 (CH King/U Kitron) and Al102918 (AD LaBeaud). 


\section{Competing interests}

The authors declare that they have no competing interests.

Received: 26 August 2015 Accepted: 19 November 2015 Published online: 01 December 2015

\section{References}

1. WHO. World malaria report 2014. Geneva: World Health Organization; 2014

2. Noor AM, Kinyoki DK, Mundia CW, Kabaria CW, Mutua JW, Alegana VA, et al. The changing risk of Plasmodium falciparum malaria infection in Africa: 2000-10: a spatial and temporal analysis of transmission intensity. Lancet. 2014:383:1739-47.

3. O'Meara WP, Bejon P, Mwangi TW, Okiro EA, Peshu N, Snow RW, et al. Effect of a fall in malaria transmission on morbidity and mortality in Kilifi, Kenya. Lancet. 2008;372:1555-62.

4. K'Oyugi BO. Effects of bed nets and anti-malaria drugs use on childhood mortality in Kenya inverted question marks malaria endemic and epidemic areas. BMC Public Health. 2015;15:34.

5. Amin AA, Zurovac D, Kangwana BB, Greenfield J, Otieno DN, Akhwale WS, et al. The challenges of changing national malaria drug policy to artemisinin-based combinations in Kenya. Malar J. 2007;6:72.

6. Noor AM, Amin AA, Akhwale WS, Snow RW. Increasing coverage and decreasing inequity in insecticide-treated bed net use among rural Kenyan children. PLoS Med. 2007;4:e255.

7. Guyatt HL, Noor AM, Ochola SA, Snow RW. Use of intermittent presumptive treatment and insecticide treated bed nets by pregnant women in four Kenyan districts. Trop Med Int Health. 2004;9:255-61.

8. Division of Malaria Control. 2010 Kenya malaria indicator survey (KMIS). Nairobi: Ministry of public health and sanitation; 2011.

9. Bouyou-Akotet MK, Mawili-Mboumba DP, Kendjo E, Mabika-Mamfoumbi $M$, Ngoungou EB, Dzeing-Ella A, et al. Evidence of decline of malaria in the general hospital of Libreville, Gabon from 2000 to 2008. Malar J. 2009;8:300.

10. Bisanzio D, Mutuku F, Bustinduy AL, Mungai PL, Muchiri EM, King CH, et al. Cross-sectional study of the burden of vector-borne and soil-transmitted polyparasitism in rural communities of Coast Province, Kenya. PLoS Negl Trop Dis. 2014;8:e2992.

11. Munga S, Yakob L, Mushinzimana E, Zhou G, Ouna T, Minakawa N, et al. Land use and land cover changes and spatiotemporal dynamics of anopheline larval habitats during a four-year period in a highland community of Africa. Am J Trop Med Hyg. 2009;81:1079-84.

12. Omukunda E, Githeko A, Ndong AM, Mushinzimana E, Yan G. Effect of swamp cultivation on distribution of anopheline larval habitats in Western Kenya. J Vector Borne Dis. 2012;49:61-71.

13. Mushinzimana E, Munga S, Minakawa N, Li L, Feng CC, Bian L, et al. Landscape determinants and remote sensing of anopheline mosquito larval habitats in the western Kenya highlands. Malar J. 2006:5:13.

14. Bejon P, Williams TN, Nyundo C, Hay SI, Benz D, Gething PW, et al. A microepidemiological analysis of febrile malaria in Coastal Kenya showing hotspots within hotspots. Elife. 2014;3:e02130.

15. Zhou G, Afrane YA, Malla S, Githeko AK, Yan G. Active case surveillance, passive case surveillance and asymptomatic malaria parasite screening illustrate different age distribution, spatial clustering and seasonality in western Kenya. Malar J. 2015:14:41

16. Kalayjian BC, Malhotra I, Mungai P, Holding P, King CL. Marked decline in malaria prevalence among pregnant women and their offspring from 1996 to 2010 on the south Kenyan Coast. Am J Trop Med Hyg. 2013:89:1129-34.

17. Okech BA, Mwobobia IK, Kamau A, Muiruri S, Mutiso N, Nyambura J, et al. Use of integrated malaria management reduces malaria in Kenya. PLoS One. 2008;3:e4050.

18. Olotu A, Fegan G, Williams TN, Sasi P, Ogada E, Bauni E, et al. Defining clinical malaria: the specificity and incidence of endpoints from active and passive surveillance of children in rural Kenya. PLoS One. 2010;5:e15569.

19. Tiono AB, Kangoye DT, Rehman AM, Kargougou DG, Kabore Y, Diarra $A$, et al. Malaria incidence in children in South-West Burkina Faso: comparison of active and passive case detection methods. PLoS One. 2014;9:e86936.

20. Francis D, Gasasira A, Kigozi R, Kigozi S, Nasr S, Kamya MR, et al. Health facility-based malaria surveillance: the effects of age, area of residence and diagnostics on test positivity rates. Malar J. 2012;11:229.

21. Aregawi M, Lynch M, Bekele W, Kebede H, Jima D, Taffese HS, et al. Time series analysis of trends in malaria cases and deaths at hospitals and the effect of antimalarial interventions, 2001-2011, Ethiopia. PLoS One. 2014;9:e106359.

22. Okiro EA, Hay SI, Gikandi PW, Sharif SK, Noor AM, Peshu N, et al. The decline in paediatric malaria admissions on the coast of Kenya. Malar J. 2007;6:151.

23. Moon AM, Biggs HM, Rubach MP, Crump JA, Maro VP, Saganda W, et al. Evaluation of in-hospital management for febrile illness in Northern Tanzania before and after 2010 World Health Organization Guidelines for the treatment of malaria. PLoS One. 2014;9:e89814.

24. WHO. Guidelines for the treatment of malaria. Geneva: World Health Organization; 2010.

25. Crump JA, Morrissey AB, Nicholson WL, Massung RF, Stoddard RA, Galloway $\mathrm{RL}$, et al. Etiology of severe non-malaria febrile illness in Northern Tanzania: a prospective cohort study. PLoS Negl Trop Dis. 2013;7:e2324.

26. O'Meara WP, Mott JA, Laktabai J, Wamburu K, Fields B, Armstrong J, et al. Etiology of pediatric fever in Western Kenya: a case-control study of falciparum malaria, respiratory viruses, and streptococcal pharyngitis. Am J Trop Med Hyg. 2015;92:1030-7.

27. LaBeaud AD, Banda T, Brichard J, Muchiri EM, Mungai PL, Mutuku FM, et al. High rates of o'nyong nyong and Chikungunya virus transmission in coastal Kenya. PLoS Negl Trop Dis. 2015;9:e0003436.

28. Stoler J, Al Dashti R, Anto F, Fobil JN, Awandare GA. Deconstructing "malaria": West Africa as the next front for dengue fever surveillance and control. Acta Trop. 2014;134:58-65.

29. Prasad N, Murdoch DR, Reyburn H, Crump JA. Etiology of severe febrile illness in low- and middle-income countries: a systematic review. PLoS One. 2015;10:e0127962.

30. Bustinduy AL, Thomas CL, Fiutem JJ, Parraga IM, Mungai PL, Muchiri EM et al. Measuring fitness of Kenyan children with polyparasitic infections using the 20-m shuttle run test as a morbidity metric. PLoS Negl Trop Dis. 2011:5:e1213.

31. Kenyan Central Bureau of Statistics. 2009 Kenya housing and population census: vol. 1 A population distribution by administrative units. 2010

32. Open Layer QGIS plugin. 2014. https://plugins.qgis.org/plugins/openlayers plugin/. Accessed 22 Aug 2014.

33. Umlauf N, Adler D, Kneib T, Lang S, Zeileis A. Structured additive regression models: An R interface to BayesX: Working Papers in Economics and Statistics. 2012.

34. Waller LA, Gotway CA. Applied spatial statistics for public health data. Wiley; 2004.

35. Onyango SA, Kitron U, Mungai P, Muchiri EM, Kokwaro E, King CH, et al. Monitoring malaria vector control interventions: effectiveness of five different adult mosquito sampling methods. J Med Entomol. 2013:50:1140-51.

36. Wood S. Generalized additive models: an introduction with R. CRC Press; 2006.

37. Burnham KP, Anderson DR. Model selection and multimodel inference: a practical information-theoretic approach. Springer Science \& Business Media; 2002.

38. Conover WJ. Practical nonparametric statistics. Wiley; 1998.

39. Qgis Development Team. QGIS Geographic Information System. 2013.

40. R Core Team. R: A language and environment for statistical computing. R Foundation for Statistical Computing. Vienna, Austria: 2014.

41. Breiman RF, Olack B, Shultz A, Roder S, Kimani K, Feikin DR, et al. Healthcare-use for major infectious disease syndromes in an informal settlement in Nairobi, Kenya. J Health Popul Nutr. 2011;29:123-33.

42. Burton DC, Flannery B, Onyango B, Larson C, Alaii J, Zhang X, et al. Healthcare-seeking behaviour for common infectious disease-related illnesses in rural Kenya: a community-based house-to-house survey. J Health Popul Nutr. 2011;29:61-70.

43. Feikin DR, Olack B, Bigogo GM, Audi A, Cosmas L, Aura B, et al. The burden of common infectious disease syndromes at the clinic and household level from population-based surveillance in rural and urban Kenya. PLoS One. 2011:6:e16085 
44. Muturi EJ, Muriu S, Shililu J, Mwangangi J, Jacob BG, Mbogo C, et al. Effect of rice cultivation on malaria transmission in central Kenya. Am J Trop Med Hyg. 2008;78:270-5.

45. Kitau J, Oxborough RM, Tungu PK, Matowo J, Malima RC, Magesa SM, et al. Species shifts in the Anopheles gambiae complex: do LLINs successfully control Anopheles arabiensis? PLoS One. 2012;7:e31481.

46. Jarju LB, Fillinger U, Green C, Louca V, Majambere S, Lindsay SW. Agriculture and the promotion of insect pests: rice cultivation in river floodplains and malaria vectors in The Gambia. Malar J. 2009;8:170.

47. Mutuku FM, King CH, Mungai P, Mbogo C, Mwangangi J, Muchiri EM, et al. Impact of insecticide-treated bed nets on malaria transmission indices on the south coast of Kenya. Malar J. 2011;10:356.

48. Curtis CF, Jana-Kara B, Maxwell CA. Insecticide treated nets: impact on vector populations and relevance of initial intensity of transmission and pyrethroid resistance. J Vector Borne Dis. 2003;40:1-8.

49. Gimnig JE, Vulule JM, Lo TQ, Kamau L, Kolczak MS, Phillips-Howard PA, et al. Impact of permethrin-treated bed nets on entomologic indices in an area of intense year-round malaria transmission. Am J Trop Med Hyg. 2003;68(4 Suppl):16-22.

50. Mutuku FM, Khambira M, Bisanzio D, Mungai P, Mwanzo I, Muchiri EM, et al. Physical condition and maintenance of mosquito bed nets in Kwale County, coastal Kenya. Malar J. 2013;12:46.

51. Maxwell CA, Rwegoshora RT, Magesa SM, Curtis CF. Comparison of coverage with insecticide-treated nets in a Tanzanian town and villages where nets and insecticide are either marketed or provided free of charge. Malar J. 2006:5:44

52. Batisso E, Habte T, Tesfaye G, Getachew D, Tekalegne A, Kilian A, et al. A stitch in time: a cross-sectional survey looking at long lasting insecticidetreated bed net ownership, utilization and attrition in SNNPR, Ethiopia. Malar J. 2012;11:183

53. Baume CA, Reithinger R, Woldehanna S. Factors associated with use and non-use of mosquito nets owned in Oromia and Amhara regional states, Ethiopia. Malar J. 2009;8:264
54. Rulisa S, Kateera F, Bizimana JP, Agaba S, Dukuzumuremyi J, Baas L, et al. Malaria prevalence, spatial clustering and risk factors in a low endemic area of Eastern Rwanda: a cross sectional study. PLoS One. 2013;8:e69443.

55. Coleman M, Mabaso ML, Mabuza AM, Kok G, Coetzee M, Durrheim DN. Household and microeconomic factors associated with malaria in Mpumalanga, South Africa. Trans R Soc Trop Med Hyg. 2010;104:143-7.

56. Ye Y, Hoshen M, Louis V, Seraphin S, Traore I, Sauerborn R. Housing conditions and Plasmodium falciparum infection: protective effect of iron-sheet roofed houses. Malar J. 2006;5:8.

57. Baragatti M, Fournet F, Henry MC, Assi S, Ouedraogo H, Rogier C, et al. Social and environmental malaria risk factors in urban areas of Ouagadougou, Burkina Faso. Malar J. 2009;8:13.

58. Alonso PL, Brown G, Arevalo-Herrera M, Binka F, Chitnis C, Collins F, et al. A research agenda to underpin malaria eradication. PLoS Med. 2011;8:e1000406.

59. Mueller I, Slutsker L, Tanner M. Estimating the burden of malaria: the need for improved surveillance. PLoS Med. 2011;8:e1001144.

60. Mangham LJ, Cundill B, Achonduh OA, Ambebila JN, Lele AK, Metoh $\mathrm{TN}$, et al. Malaria prevalence and treatment of febrile patients at health facilities and medicine retailers in Cameroon. Trop Med Int Health. 2012;17:330-42.

61. Nadjm B, Mtove G, Amos B, Walker NF, Diefendal H, Reyburn H, et al. Severe febrile illness in adult hospital admissions in Tanzania: a prospective study in an area of high malaria transmission. Trans R Soc Trop Med Hyg. 2012;106:688-95

62. Ellis EM, Neatherlin JC, Delorey M, Ochieng M, Mohamed AH, Mogeni DO, et al. A household serosurvey to estimate the magnitude of a dengue outbreak in Mombasa, Kenya, 2013. PLoS Negl Trop Dis. 2015;9:e0003733.

\section{Submit your next manuscript to BioMed Central and we will help you at every step:}

- We accept pre-submission inquiries

- Our selector tool helps you to find the most relevant journal

- We provide round the clock customer support

- Convenient online submission

- Thorough peer review

- Inclusion in PubMed and all major indexing services

- Maximum visibility for your research

Submit your manuscript at www.biomedcentral.com/submit 